\title{
Rancang Bangun Wireless Electronic Nose Berbasis Teknologi Internet of Things
}

\author{
Dwita Mido Gumelar, Muhammad Rivai, Tasripan \\ Departemen Teknik Elektro, Fakultas Teknologi Elektro, Institut Teknologi Sepuluh Nopember \\ e-mail: muhammad_rivai@ee.its.ac.id
}

\begin{abstract}
Abstrak-Identifikasi kandungan gas atau uap diperlukan pada banyak bidang aplikasi terutama pada industri pengolahan minyak dan gas. Sistim identifikasi diperlukan karena adanya beberapa cairan berbahaya yang mudah menguap dengan bau yang khas seperti minyak bahan bakar dan alkohol. Pada umumnya proses identifikasi gas membutuhkan proses yang lama, kompleks serta mahal karena diperlukan sampel dari lapangan dan analisa di laboratorium. Oleh karena itu dibutuhkan alat pengidentifikasian gas yang dapat dipantau dimana saja secara real time. Pada penelitian ini telah dirancang dan dibuat sebuah pengembangan dari sistem electronic nose yang ditempatkan di lingkungan industri. Sistem ini menggunakan deret sensor semikonduktor yang berbeda yaitu MQ-2, MQ-9 dan MQ-135. Peralatan ini dilengkapi teknologi yang berbasis internet of things dengan menggunakan single board computer Raspberry $P i$ 3. Hasil pengujian menunjukan bahwa sistem ini dapat mengidenifikasi alkohol, minyak tanah dan bensin dengan tingkat kesalahan 10\%. Sistem ini diharapakan dapat mengurangi resiko kebaran, ledakan, gangguan kesehatan dan pencemaran lingkungan.
\end{abstract}

Kata Kunci-Deret Sensor Semikonduktor, Internet of Things, Raspberry Pi.

\section{PENDAHULUAN}

$\mathrm{I}$ DENTIFIKASI jenis gas atau uap berbahaya sangat Ldiperlukan pada banyak bidang seperti di industri pengolahan minyak dan gas maupun rumah tangga. Hal ini dibutuhkan karena adanya beberapa cairan berbahaya yang mudah menguap dengan bau yang khas seperti bensin, solar, minyak tanah, dan alkohol. Biasanya proses identifikasi gas membutuhkan proses yang lama dan kompleks serta mahal karena diperlukan pengambilan sampel dari lapangan dan menganalisanya di laboratorium. Metode ini akan memakan waktu yang cukup lama terutama untuk mengidentifikasi kebocoran gas. Selain berbahaya karena dapat menyebabkan kebakaran, beberapa cairan seperti alkohol, minyak tanah dan premium juga berbahaya bagi kesehatan. Jika gas tersebut terhirup dengan jangka waktu yang lama dapat menyebabkan iritasi pada saluran pernapasan dan menyebabkan kanker.

Saat ini sudah berkembang juga robot yang dapat mengidentifikasi gas yang dapat menginspeksi adanya gas. Namun robot menemui kesulitan untuk melewati medan yang berkondisi berat. Maka dari itu dibutuhkan alat pengidentifikasi jenis gas yang dapat dipantau dimana saja secara real time.

Perkembangan teknologi mengenai sistem electronic nose sudah sangat luas dan umum digunakan untuk berbagai bidang. Sistem electronic nose berdasarkan sensor metal oxide semiconductor digunakan sebagai teknik alternatif untuk klasifikasi tingkat kebusukan dari daging merah [1], pemantauan kesegaran sarden maroko dengan neural network yang berbasis sistem electronic nose [2]. Berbagai jenis electronic nose nirkabel telah dikembangkan oleh para peneliti dalam sepuluh tahun terakhir [3]. Pada penelitian ini telah dirancang sebuah prototip dari sebuah electronic nose berbasiskan teknologi internet of things dan single board computer.

\section{DASAR TEORI}

A. Gas

Bahan kimia mudah terbakar merupakan bahan yang mudah bereaksi dengan oksigen dan dapat menimbulkan kebakaran yang sangat besar. Reaksi kebakaran yang cepat juga dapat menghasilkan suatu ledakan. Bahan cair dinyatakan mudah terbakar bila titik nyala lebih dari $21^{\circ} \mathrm{C}$ dan $55^{\circ} \mathrm{C}$ pada tekanan $1 \mathrm{~atm}$ dan dinyatakan sangat mudah terbakar jika titik didih kurang dari $20^{\circ} \mathrm{C}$ pada tekanan $1 \mathrm{~atm}$.

Tabel 1.

\begin{tabular}{|c|c|c|c|c|c|c|c|}
\hline No. & $\overline{\text { Pelarut }}$ & $\begin{array}{l}\text { Daerah } \\
\text { kons \% } \\
\text { mudah } \\
\text { terbakar }\end{array}$ & $\begin{array}{c}\text { Titik } \\
\text { didih }^{\circ} \\
\text { C }\end{array}$ & $\begin{array}{c}\text { Titik } \\
\text { Nyala }^{\circ} \\
\text { C }\end{array}$ & $\begin{array}{c}\text { Titik } \\
\text { nyala }^{\circ} \\
\text { C }\end{array}$ & $\begin{array}{c}\mathrm{W} \\
\text { cairan }\end{array}$ & $\begin{array}{c}\text { W } \\
\text { uap }\end{array}$ \\
\hline 1. & Aseton & $3-13$ & 55 & -18 & 538 & 0.79 & 2.0 \\
\hline 2. & Benzena & L4-8 & 80 & -11 & 562 & 0.88 & 2.8 \\
\hline 3. & Bensin & $14-7.6$ & $\begin{array}{l}38- \\
204\end{array}$ & -43 & $\begin{array}{c}280- \\
456\end{array}$ & 0.8 & 3.04 \\
\hline 4. & $\begin{array}{c}\text { Etil } \\
\text { alkohol }\end{array}$ & $13-19$ & 79 & 12 & 432 & 0.79 & 1.59 \\
\hline 5. & Etil eter & $1.84-48$ & 34 & -45 & 180 & 0.71 & 2.55 \\
\hline 6. & Heksena & LP7.5 & 68 & -22 & 261 & 0.66 & 2.97 \\
\hline 7. & $\begin{array}{l}\text { Karbon } \\
\text { sulfida }\end{array}$ & $1-44$ & 46 & -30 & 100 & 1.26 & 2.6 \\
\hline 8. & Metanol & $6-36.5$ & 65 & 12 & 464 & 0.79 & 1.1 \\
\hline 9. & $\begin{array}{l}\text { Metil etil } \\
\text { keton }\end{array}$ & $2-10$ & 80 & -7 & 515 & 01.81 & 2.5 \\
\hline 10. & petroleuin & $1-6$ & $30-60$ & -57 & 288 & 0.6 & 2.5 \\
\hline
\end{tabular}

B. Sensor Gas

Sensor gas semikonduktor terdiri dari elemen sensor, dasar sensor dan tudung sensor [4]. Elemen sensor terdiri dari bahan sensor dan bahan pemanas. Elemen sensor menggunakan bahan seperti timah (IV) oksida $\mathrm{S}_{\mathrm{n}} \mathrm{O}_{2}$, wolfram (VI) oksida $\mathrm{WO}_{3}$, dan lainnya. Bila suatu kristal oksida logam seperti $\mathrm{S}_{\mathrm{n}} \mathrm{O}_{2}$ dipanaskan pada suhu tinggi tertentu di udara, oksigen akan teradsorpsi pada permukaan kristal dengan muatan negative yang diakibatkan oleh adanya elektron donor pada permukaan kristal yang ditransfer ke oksigen teradsorpsi. Hal ini akan menghasilkan suatu potensial permukaan yang dapat 
menghambat aliran elektron yang memunculkan tahanan listrik.

\section{Single Board Computer}

Single Board Computer (SBC) adalah sebuah komputer lengkap yang dibangun di atas sebuah papan sirkuit tunggal dengan mikroprosesor, memori, input / output (I/O) dan fitur lain yang dibutuhkan dari sebuah komputer fungsional. SBC didasarkan pada hampir semua mikroprosesor yang tersedia, dan dapat dibangun dari logika diskrit atau programmable logic. Berbeda dengan desktop dan komputer pribadi, SBC tidak bergantung pada slot ekspansi untuk fungsi perifer atau ekspansi dan sebagai pengganti telah disedialkan pin Generalpurpose input/output (GPIO).

Raspberry Pi (atau Raspi) adalah sebuah SBC berukuran kartu kredit yang dihubungkan ke TV via HDMI dan keyboard. Sebagai Internet of Things (IoT), komputer kecil ini mampu digunakan untuk menjalankan spreadsheet, pengolah kata dan permainan, terutama untuk memainkan video definisi tinggi.

Desain Raspi didasarkan seputar System-on-a-chip (SoC) Broadcom BCM2835, yang telah tertanam prosesor ARM1176JZF-S dengan kecepatan $700 \mathrm{MHz}$, VideoCore IV GPU, dan 256 Megabyte RAM (model B). Penyimpanan data didisain tidak untuk menggunakan hard disk atau solid-state drive, melainkan mengandalkan kartu SD untuk booting dan penyimpanan jangka panjang. Raspi utamanya menjalankan sistem operasi berbasis kernel Linux.

Sistem operasi utama Raspi menggunakan Debian GNU/Linux, mengemas Iceweasel, kaligrafi Suite dan bahasa pemrograman Python. Sejumlah distro lainnya, termasuk distro buatan Indonesia BlankOn Linux yang juga telah menyediakan versi arstektur ARM dan bisa dijalankan di Raspi. Hardware Raspberry Pi tidak memiliki real-time clock, sehingga OS harus memanfaatkan timer jaringan server sebagai pengganti. Namun komputer yang mudah dikembangkan ini dapat ditambahkan dengan fungsi real-time (seperti DS1307) dan banyak lainnya melalui saluran GPIO via antarmuka Inter-Integrated Circuit $\left(\mathrm{I}^{2} \mathrm{C}\right)$.

GPIO merupakan suatu modul pin pada sirkuit terpadu yang perilakunya dapat di kontrol melalui software. Pin GPIO tidak ditetapkan untuk tujuan khusus dan secara default tidak digunakan. Ide dibalik GPIO adalah untuk memenuhi sistem integrator dalam memperluas dan membangun sistem lengkap yang membutuhkan pin tambahan dari chip berupa sinyal kontrol ataupun data. Adanya konektor (pin) yang tersedia dari chip dapat menghemat kerumitan saat mengatur sirkuit tambahan

Analog to Digital Converter (ADC) adalah pengubah input analog menjadi kode digital. ADC banyak digunakan sebagai pengatur proses industri, komunikasi digital dan rangkaian pengukuran. Umumnya ADC digunakan sebagai perantara antara sensor yang kebanyakan analog dengan sistim komputer.

\section{Komunikasi SPI}

Serial Peripheral Interface (SPI) merupakan salah satu mode komunikasi serial synchrounous. Komunikasi SPI membutuhkan 3 jalur yaitu MOSI, MISO, dan SCK. Melalui komunikasi ini data dapat saling dikirimkan baik antar mikrokontroller maupun antara mikrokontroller dengan peripheral lain.

\section{E. Neural Network}

Neural network (NN) merupakan salah satu metoda penting dalam artificial intelligence (AI) yang meniru kinerja otak manusia yang sudah diaplikasikan di berbagai bidang [5]. Menurut Haykin, NN merupakan sejumlah besar prosesor yang terdistribusi secara pararel dan terdiri dari unit pemrosesan sederhana, dimana masing-masing unit memiliki kecenderungan untuk menyimpan pengetahuan yang dialami dan dapat digunakan kembali [6].

Menurut Kevin Gurney, sebuah NN merupakan pertemuan saling berhubungan dari elemen pemrosesan sederhana, unit atau node, yang fungsinya didasarkan pada neuron hewan. Pengolahan kemampuan jaringan disimpan dalam antar-satuan kekuatan sambungan atau bobot yang diperoleh dengan proses adaptasi atau belajar dari satu set pelatihan pola [7]. Gambar 1 menunjukkan model sebuah neuron. Fungsi sigmoid biner sering digunakan untuk menentukan keputusan akhir sebuah neuron yang dinyatakan:

$$
f_{1}(x)=\frac{1}{\left(1+e^{-x}\right)}
$$

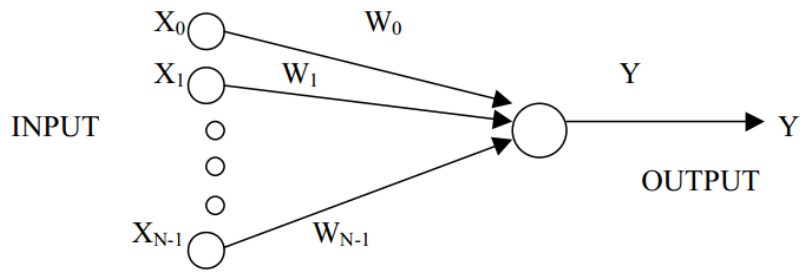

Gambar 1. Model sebuah neuron

\section{F. Internet of Things}

Gambar 2. Internet of Things

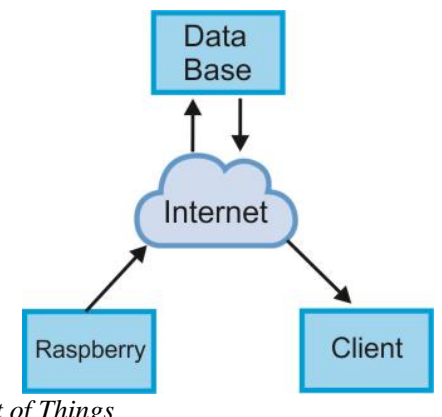

Internet of things (IoT) adalah sebuah sistem dimana bendabenda di dunia fisik dapat dihubungkan ke internet oleh sensor [8], ditunjukkan pada Gambar 2. IoT mengacu pada penggunaan perangkat dan sistem cerdas yang terhubung untuk memanfaatkan data yang dikumpulkan oleh sensor dan actuator yang tertanam di mesin dan benda fisik lainnya. Manusia tidak akan perlu lagi mengatur mesin saat menggunakannya, tetapi mesin tersebut dapat mengatur dirinya sendiri dan berinteraksi dengan mesin lain yang dapat berkolaborasi dengannya.

Pada IoT setiap benda harus memiliki sebuah IP address. IP address adalah sebuah identitas dalam jaringan yang membuat benda tersebut bisa diperintahkan dari peralatan lain dalam 
jaringan yang sama. IP address dalam setiap peralatan tersebut akan dikoneksikan ke jaringan internet.

\section{PERANCANGAN SISTEM}

Secara umum, sistem terdiri atas perangkat keras dan perangkat lunak. Perangkat keras dari sistem berupa blok modul sensor, minimum sistem Raspberry $\mathrm{Pi}$, valve dan pompa udara, ditunjukkan pada Gambar 3. Sedangkan perangkat lunak terdiri atas program pembacaan ADC, pengaturan valve dan sistem neural network. Gambar 4 menunjukkan diagram blok dari system yang dibuat.

Deret sensor gas dihubungkan ke Single Board Computer dengan perantara IC MCP3008 sebagai piranti ADC melalui pin GPIO Raspberry Pi. Data sensor akan dianalisis lebih lanjut dengan $\mathrm{NN}$ untuk identifikasi jenis gas yang diujikan. Hasil tersebut akan ditampilkan secara langsung melalui GUI pada Raspberry Pi dalam bentuk grafik.

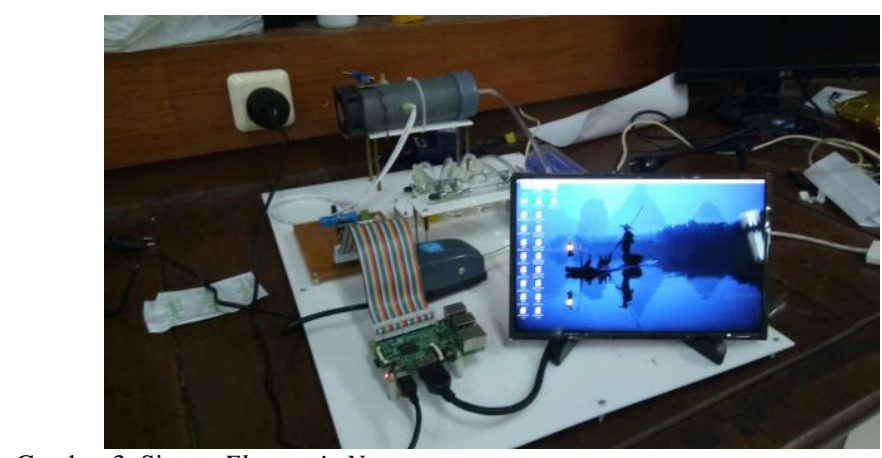

Gambar 3. Sistem Electronic Nose

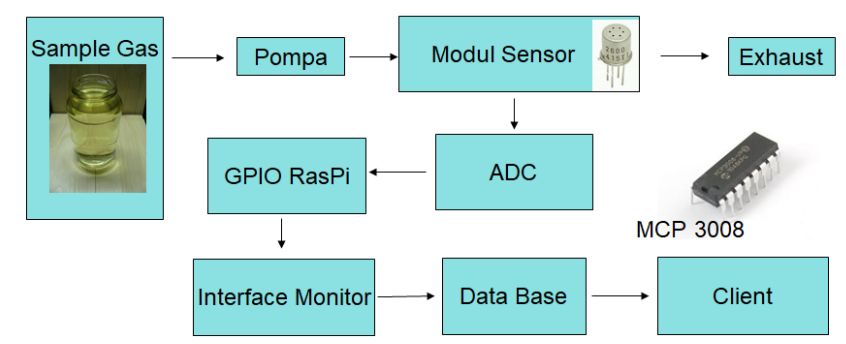

Gambar 4. Diagram blok sistem.

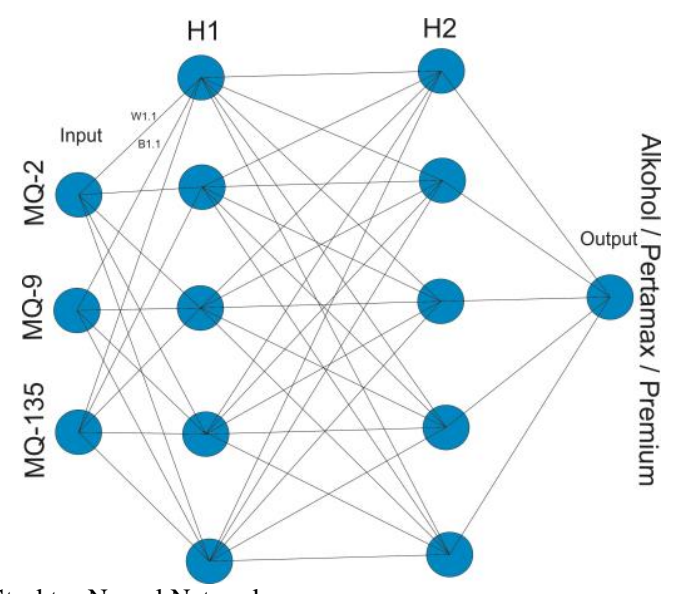

Gambar 5. Struktur Neural Network
Untuk struktur neural network yang digunakan untuk mengidentifikasi gas dapat dilihat pada gambar 5. Terdapat 3 node input yang digunakan, 2 hidden layer yang masing masing terdapat 5 neuron dan 1 neuron output.

\section{PENGUJIAN DAN PEMBAHASAN}

Udara dipompa masuk ke dalam silica gel untuk memperoleh udara yang bebas dari uap air. Kemudian udara bersih tersebut dilewatkan ke dalam tabung sensor sehingga setiap sensor menghasilkan respon yang stabil, ditunjukkan pada Gambar 6.

Gambar 7 menunjukkan pengujian sensor gas terhadap uap bensin. Terlihat bahwa sensor gas MQ-2 memiliki respon yang paling cepat dibandingkan dengan sensor MQ-9 dan MQ-135. Sensor MQ-2 juga memiliki nilai tegangan maximum yang paling besar. Pada pengujian ini dibutuhkan waktu 20 detik untuk dapat mendeteksi gas premium dengan jarak sumber gas $10 \mathrm{~cm}$. Pada percobaan ini dibutuhkan waktu pengosongan 1 menit 57 detik agar dapat dilakukan pengujian terhadap gas uji yang lain. Pengujian uap minyak tanah dan alkohoh masingmasing ditunjukkan pada Gambar 8 dan 9.

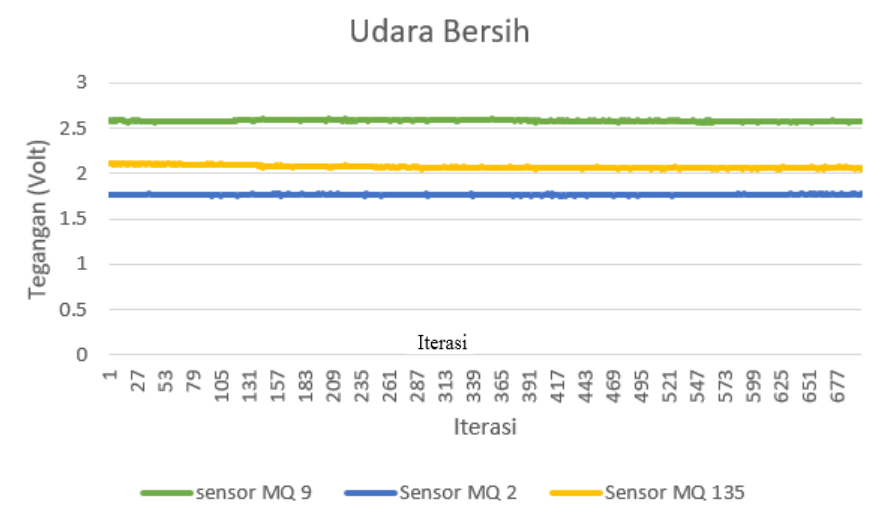

Gambar 6. Hasil Pengujian Udara Bersih

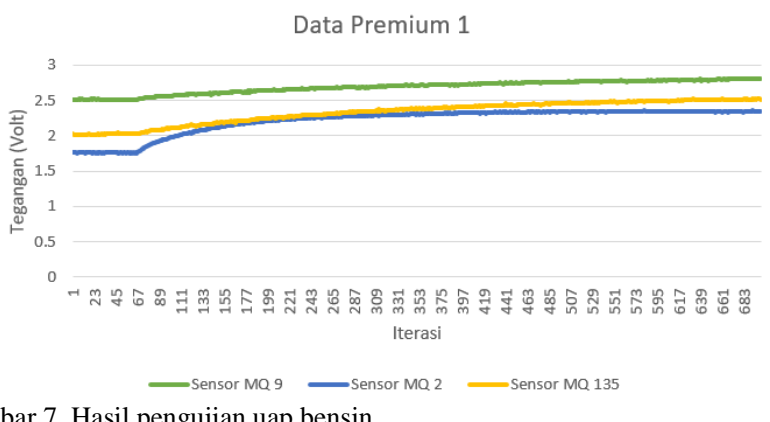

Gambar 7. Hasil pengujian uap bensin 


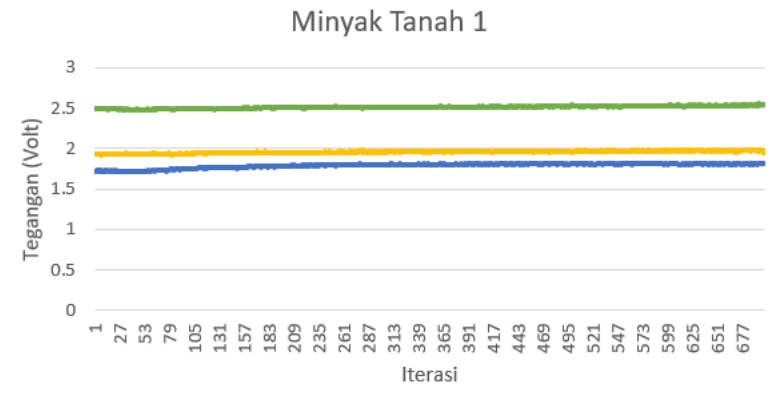

- Sensor MQ 9 Sensor MQ 2 Sensor MQ 135

Gambar 8. Hasil pengujian uap minyak tanah

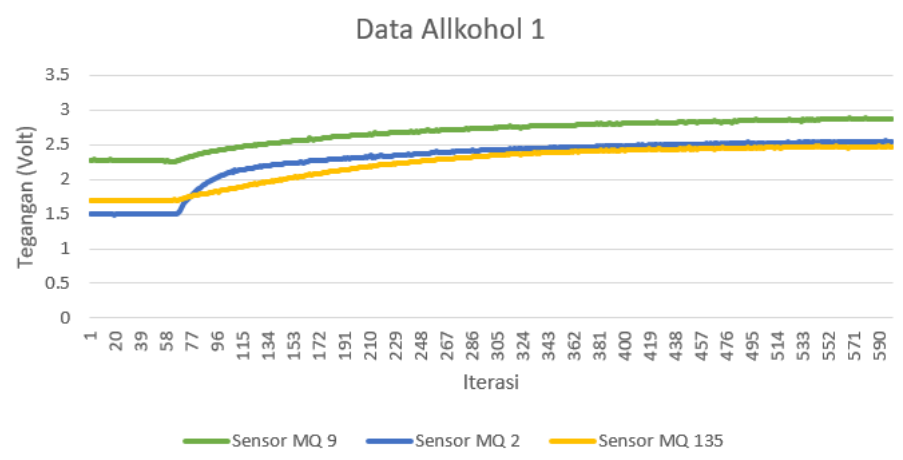

Gambar 9. Hasil pengujian uap alkohol

Pada proses pelatihan NN menggunakan sebaran masukan gas uji yang digunakan, ditunjukkan pada Tabel 2 sampai Tabel 5. Data yang digunakan untuk pembelajaran terdapat 40 data input dan data target. Nilai error saat pelatihan adalah sebesar 0,00001. Proses pembelajaran dilakukan di komputer pribadi. Hal ini bertujuan untuk mempercepat proses untuk mendapatkan weight dan bias yang dibutuhkan untuk klasifikasi. Gambar 10 menunjukkan grafik dari hasil pembelajaran. Hasil pelatihan ini menunjukkan bahwa data target dan hasil aktual tidak jauh berbeda. Error pembelajaran dapat dilihat pada Gambar 11 yang mana nilai rata-rata dari error pembelajaran $\mathrm{NN}$ adalah -0.000168077 . Tabel 6 menunjukkan hasil klasifikasi jenis gas dari 10 kali pengujian secara acak pada setiap jenis gas uji.

Tabel 2.

Nilai input NN udara bersih

\begin{tabular}{ccccc}
\hline \hline Target & No & Sensor 1 & Sensor 2 & Sensor 3 \\
\hline 1 & Data Input 1 & 2.58648 & 1.76979 & 2.06692 \\
1 & Data Input 2 & 2.57916 & 1.76391 & 2.06355 \\
1 & Data Input 3 & 2.55179 & 1.75901 & 2.03516 \\
1 & Data Input 4 & 2.54837 & 1.75656 & 2.03565 \\
1 & Data Input 5 & 2.5367 & 1.75316 & 2.02398 \\
1 & Data Input 6 & 2.53278 & 1.75171 & 2.02638 \\
1 & Data Input 7 & 2.52788 & 1.74734 & 2.01712 \\
1 & Data Input 8 & 2.52494 & 1.74831 & 2.01762 \\
1 & Data Input 9 & 2.5171 & 1.75316 & 2.01811 \\
1 & Data Input 10 & 2.5171 & 1.75316 & 2.01566 \\
\hline \hline
\end{tabular}

Tabel 3.

Nilai input NN uap bensin

\begin{tabular}{ccrrr}
\hline \hline Target & No & Sensor 1 & Sensor 2 & Sensor 3 \\
\hline 3 & Data Input 1 & 2.68867 & 2.28544 & 2.3475 \\
3 & Data Input 2 & 2.73316 & 2.32552 & 2.41303
\end{tabular}

\begin{tabular}{rrrrr}
3 & Data Input 3 & 2.76003 & 2.06986 & 2.2928 \\
3 & Data Input 4 & 2.78884 & 2.1163 & 2.3656 \\
3 & Data Input 5 & 2.74386 & 1.9844 & 2.25026 \\
3 & Data Input 6 & 2.77514 & 2.0137 & 2.32307 \\
3 & Data Input 7 & 2.7468 & 1.94672 & 2.219 \\
3 & Data Input 8 & 2.77466 & 1.9746 & 2.28593 \\
3 & Data Input 9 & 2.74386 & 1.93501 & 2.20626 \\
3 & Data Input 10 & 2.7659 & 1.95696 & 2.26394 \\
\hline \hline
\end{tabular}

Tabel 4.

Nilai input NN uap minyak tanah

\begin{tabular}{ccrrr}
\hline \hline Target & No & Sensor 1 & Sensor 2 & Sensor 3 \\
\hline 2 & Data Input 1 & 2.51122 & 1.80056 & 1.95892 \\
2 & Data Input 2 & 2.51857 & 1.80546 & 1.9648 \\
2 & Data Input 3 & 2.51122 & 1.77224 & 1.94526 \\
2 & Data Input 4 & 2.5171 & 1.78204 & 1.95256 \\
2 & Data Input 5 & 2.51759 & 1.76832 & 1.94867 \\
2 & Data Input 6 & 2.52494 & 1.77567 & 1.94864 \\
2 & Data Input 7 & 2.50632 & 1.7693 & 1.93844 \\
2 & Data Input 8 & 2.51122 & 1.77714 & 1.94624 \\
2 & Data Input 9 & 2.5269 & 1.76097 & 1.94138 \\
2 & Data Input 10 & 2.52886 & 1.7693 & 1.94674 \\
\hline \hline
\end{tabular}

Tabel 5.

Nilai input NN uap alkohol

\begin{tabular}{ccrrr}
\hline \hline Target & No & Sensor 1 & Sensor 2 & Sensor 3 \\
\hline 1 & Data Input 1 & 2.74288 & 2.42569 & 2.347 \\
1 & Data Input 2 & 2.80794 & 2.48633 & 2.42131 \\
1 & Data Input 3 & 2.86606 & 2.8788 & 2.66762 \\
1 & Data Input 4 & 2.91006 & 2.93546 & 2.73024 \\
1 & Data Input 5 & 2.89056 & 2.69307 & 2.53618 \\
1 & Data Input 6 & 2.9277 & 2.7468 & 2.5948 \\
1 & Data Input 7 & 2.89154 & 2.53424 & 2.39784 \\
1 & Data Input 8 & 2.92427 & 2.58991 & 2.45456 \\
1 & Data Input 9 & 2.84705 & 2.40813 & 2.29132 \\
1 & Data Input 10 & 2.8886 & 2.45359 & 2.34116 \\
\hline \hline
\end{tabular}

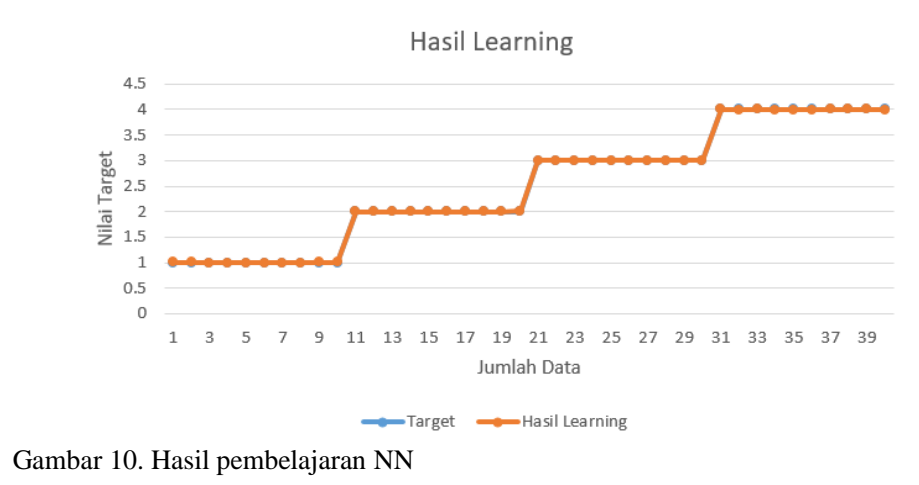




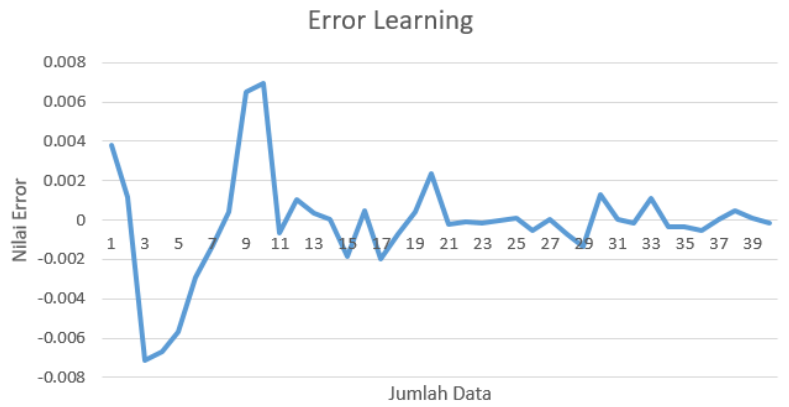

Gambar 11. Error pada pembelajaran NN

Tabel 6.

Hasil pengujian proses Neural Network

\begin{tabular}{|c|c|c|c|c|c|}
\hline No & Sensor 1 & $\begin{array}{c}\text { Sensor } \\
2\end{array}$ & Sensor 3 & $\begin{array}{c}\text { Gas Yang } \\
\text { Diuji }\end{array}$ & Hasil \\
\hline 1 & 2.0235 & 1.4272 & 1.5494 & $\begin{array}{c}\text { Minyak } \\
\text { Tanah }\end{array}$ & Alkohol \\
\hline 2 & 2.4242 & 1.5591 & 1.6129 & Bensin & Bensin \\
\hline 3 & 2.6442 & 1.5885 & 1.7429 & Bensin & Bensin \\
\hline 4 & 2.9619 & 2.1701 & 2.678 & Alkohol & Alkohol \\
\hline 5 & 2.1087 & 1.4956 & 1.6178 & $\begin{array}{c}\text { Minyak } \\
\text { Tanah }\end{array}$ & Minyak Tanah \\
\hline 6 & 2.8935 & 3.1638 & 2.1017 & Alkohol & Alkohol \\
\hline 7 & 2.0723 & 1.4956 & 1.608 & $\begin{array}{l}\text { Minyak } \\
\text { Tanah }\end{array}$ & Minyak Tanah \\
\hline 8 & 2.6532 & 1.5621 & 1.7422 & Bensin & Bensin \\
\hline 9 & 2.6689 & 2.0479 & 1.9648 & Alkohol & Alkohol \\
\hline 10 & 2.1845 & 1.4603 & 1.5885 & $\begin{array}{c}\text { Minyak } \\
\text { Tanah }\end{array}$ & Minyak Tanah \\
\hline
\end{tabular}

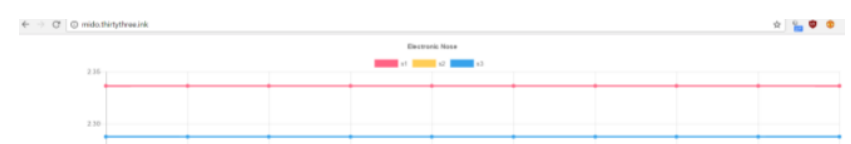

[4] M. Pinem, "Analisa Kemurnian Premium Dengan Sensor Gas TGS 2620," Universitas Sumatra Utara, 2010.

[5] Q. He, "Neural Network and Its Application in IR," University of Illinois, 1999.

[6] H. S, "Neural Network: A Comprehensive Foundation," p. 12, 1998.

[7] G. K, "An Introduction to Neural Networks," p. 13, 1997.

[8] A. Kevin, “That 'Internet of Things' Thing," RFID J., 2009.

Gambar 12. Tampilan web untuk respon sensor dan hasil klasifikasi NN 